\title{
Genetic variability and differentiation among founder populations of the pitcher plant (Sarracenia purpurea L.) in Ireland
}

\author{
J. B. Taggart* ${ }^{*} \ddagger$ \\ S. F. McNally* and \\ P. M. Sharp
}

* School of Botany and $\dagger$ Department of Genetics, University of Dublin, Trinity College, Dublin 2, Ireland.

The pitcher plant (Sarracenia purpurea L.), a native North American species, presently grows on six sites in Ireland, these being the result of transplants (founder events) from an initial introduction to Termonbarry Bog in 1906. The extent and organisation of genetic variability among these populations was examined in this study.

Of 25 enzyme systems investigated by starch gel electrophoresis, 14 showed specific activity. Eighteen loci suitable for routine population screening were identified. Diallelic polymorphisms were observed at three loci, $\mathrm{Pgm}$, $6 \mathrm{Pg}$, and Mdh-4. Genetic polymorphism at the $P$ gm locus has not previously been described.

The overall level of genetic variation ( $\max P=17$ per cent; $\max \tilde{H}_{\exp }=0.060$ ) in Irish populations was low, but nevertheless within the range recorded for native North American populations. While it was evident that the severe founder events ( $2-4$ individuals) had reduced the number of polymorphic loci there was lesser impact on heterozygosity levels. Significant genetic differentiation among populations was found at all three polymorphic loci.

\section{INTRODUCTION}

Natural populations of plants and animals may go through bottlenecks where numbers are greatly reduced. Often this will constitute a founding event when a few individuals colonise a new territory, and is followed by a population "flush" as numbers increase sharply again, until the carrying capacity of the new environment is reached. During such "founder-flush" events there is potential for the genetic basis of the derived population to change dramatically, both as a result of sampling effect in the bottleneck itself and in subsequent generations through genetic drift and possible relaxation of selection pressures.

A critical part of the process involves the founding event, in particular how many individuals are involved-and to what extent genetic differentiation actually occurs as a result of the sampling effect. This has been well examined experimentally, under laboratory conditions, e.g., in Drosophila (Powell, 1978). However, very little is known about wild populations as reliable data

$\ddagger$ Present address: School of Biology and Biochemistry, The Queen's University of Belfast, David Keir Building, Belfast BT9 5AG, N. Ireland. concerning the founding event are rarely available. An exception is a small study of one population of the pitcher plant (Sarracenia purpurea L.) in Ohio, U.S.A., known to have been founded (artificially, but since growing wild) from a single plant in 1912 (Schwaegerle and Schaal, 1979). Evidence of genetic differentiation, including a reduction in heterozygosity, compared with ten other North American populations, was noted. This work was based on a limited electrophoretic study, only seven enzymes (ten loci) being screened.

A similar founding event involving $S$. purpurea was carried out in Ireland early this century. Also, however, a number of subsequent transplantations (further founding events) to geographically isolated sites have been carried out. These have been well documented (summarised by Foss and O'Connell, 1985). This situation thus provided the opportunity to study the genetic consequences of repeated founding events in "wild" populations. The aim of the present investigation was to determine the levels of genetic variability and differentiation in introduced populations of pitcher plants in Ireland through an extensive electrophoretic survey. 
Table 1 History and present status of $S$. purpurea in Ireland

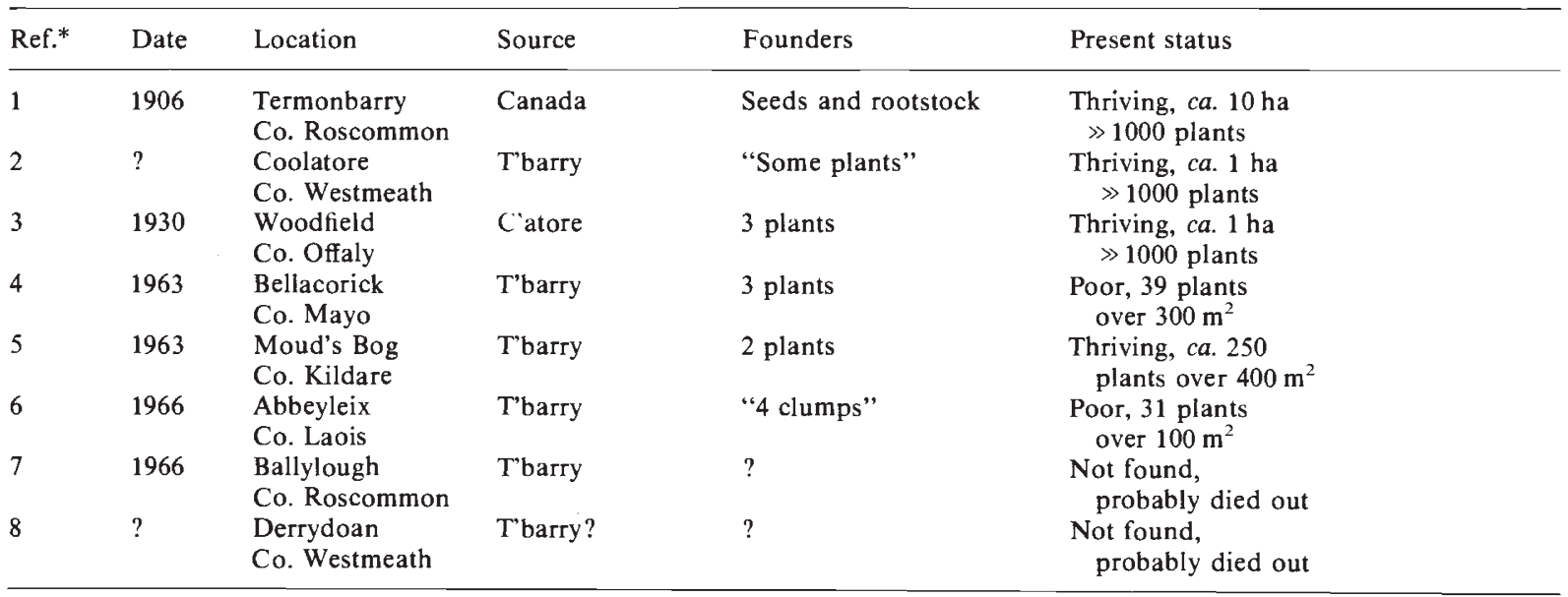

* (1) Praeger (1932); (2) Kertland (1968); (3) Kertland (1968); (4) Kertland (1968); (5) Foss and O’Connell (1984); (6) Nelson and De Vesci (1981); (7) Newell (1968); (8) Foss and O'Connell (1985).

\section{MATERIALS AND METHODS}

\section{History of introductions}

S. purpurea was first successfully introduced into Ireland in 1906 (Praeger, 1932; Foss and O'Connell, 1985). An unrecorded number of seeds and rootstock of Canadian origin were planted in Termonbarry Bog, Co. Roscommon. The plants flourished on this site becoming established over some 35 hectares (Kertland, 1968). While commercial peat cutting has reduced its present range to $c a$. 10 ha. Termonbarry remains by far the largest pitcher plant colony in Ireland.

Seven transplants from this original founding stock have been documented, the details of which are summarised in table 1 and fig. 1. Extensive searches at Ballylough and Derrydoan failed to uncover any $S$. purpurea. It is probable, as reported by Foss and O'Connell (1985), that the plants have died out at these sites. Bog drainage at both sites is a likely cause. Of the five extant transplants four were founded directly from plants taken from Termonbarry Bog. The Woodfield population, founded from plants from Coolatore, is the result of a repeated founder event.

\section{Sampling}

Hood tissue from healthy pitchers was routinely taken though other tissues (petal, flower stalk, pollen, root and pitcher stem) were also investigated. Samples were stored at $5^{\circ} \mathrm{C}$ until used, usually within two days. Preliminary work to establish satisfactory electrophoretic protocols was

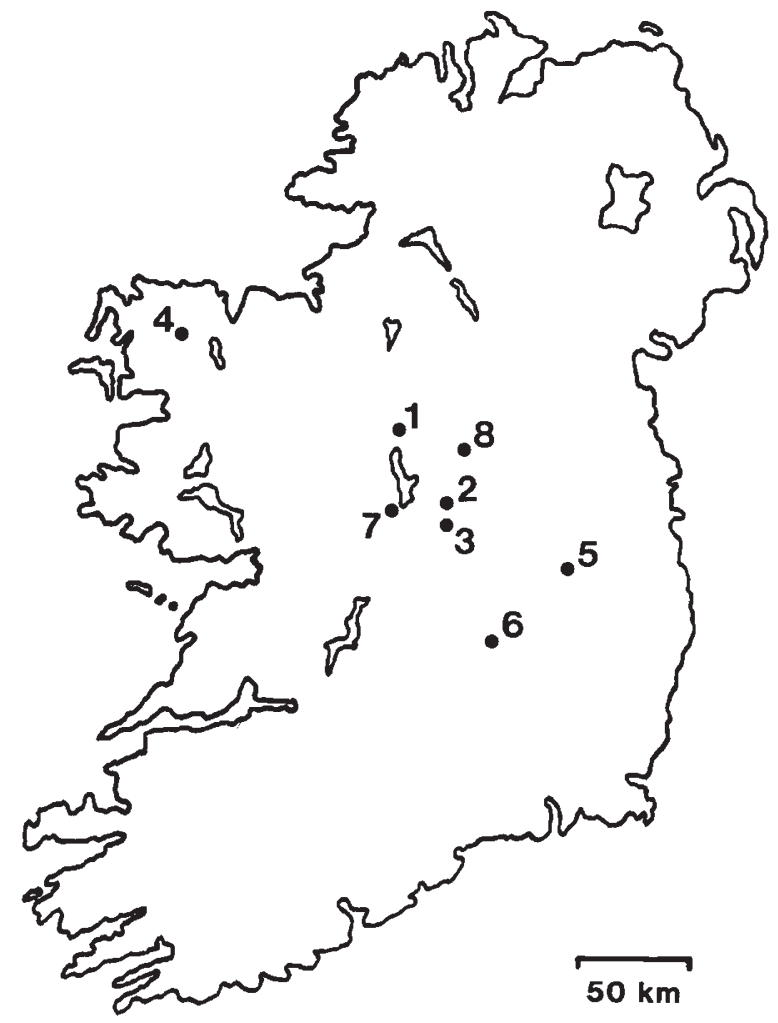

Figure 1 Documented sites for the occurrence of $S$. purpurea populations in Ireland. (Reference key is given in table 1.)

confined to pitcher plant samples from Termonbarry. During the later systematic population screening the entire populations from Abbeyleix $(n=31)$ and Bellacorick $(n=39)$ were sampled. 
For each of the four much larger populations 100 plants were sampled. Each site was divided into four roughly equal sized sectors and 25 plants were sampled at random from within each sector.

\section{Electrophoresis}

Plant tissue was diced and then milligram quantities were hand homogenised in an equal volume of extracting buffer $(0.5 \mathrm{M}$ phosphate, $p \mathrm{H} 7 \cdot 0$, containing 0.5 per cent 2-mercaptoethanol). Before homogenising, an equal weight of caffeine (to tissue) was added to sequester phenolic compounds. Extracts not so treated yielded little enzyme activity.

Horizontal starch gel electrophoresis (12 per cent starch) was performed as described by Ferguson (1980). Three main buffer systems were employed, detailed in table 2. Following electrophoresis gels were sliced into 3-5 horizontal slices and histochemically stained for specific enzyme activity. Twenty five enzymes were investigated, staining recipes being taken from Harris and Hopkinson (1976) and Vallejos (1983).

\section{Genetic nomenclature}

Following standardised nomenclature a gene locus is referred to by a set of initials, e.g. $M d h$, while the capitalised abbreviation, e.g., $M D H$, refers to its protein (enzyme) product. Multiple loci are identified by hyphenated numerals, e.g. Mdh-2, numbered sequentially from the most cathodally migrating protein product. Alleles, in parentheses, are designated according to the relative electrophoretic mobility of their protein products, the most common allele being arbitrarily termed "100". Thus, for example, Mdh-2 (100/50) refers to a heterozygote genotype at the $M d h-2$ locus involving a variant allele whose homomeric enzyme product migrates half as far as the homomeric product of the common allele.

\section{Genetic analyses}

Allele frequencies were determined by direct allele counting. The $G$ statistic (with Yate's correction where appropriate) was used to compare observed genotype numbers with those expected under Hardy-Weinberg equilibrium (Ferguson, 1980). Proportion of polymorphic loci $(P, 99$ per cent criterion), number of alleles per locus and observed and calculated heterozygosity ( $H_{\text {obs }}$ and $H_{\text {exp }}$ ) were computed by standard methods (Ferguson, 1980). Gametic phase equilibrium among loci was examined by linkage disequilibrium analysis, employing the maximum likelihood procedure of Hill (1974).

Inter-population genetic diversity was investigated using two standard measures. Single locus

Table 2 Details of electrophoretic buffers routinely used in this study

(1) TCB (Ferguson, 1980)

$\begin{array}{ll}\text { Electrode: } & 0.3 \mathrm{M} \text { boric acid } \\ (p \mathrm{H} 8.6) & 0.1 \mathrm{M} \text { lithium hydroxide } \\ \text { Gel: } & 0.076 \mathrm{Tris} \\ (p \mathrm{H} 8.6) & 0.005 \mathrm{M} \text { citric acid } \\ & 0.015 \mathrm{M} \text { boric acid } \\ & 0.005 \mathrm{M} \text { lithium hydroxide }\end{array}$

Gels were run for 5 hours at $40 \mathrm{~mA}$ constant current

(2) CAM (Clayton \& Tretiak, 1972)

Electrode: $\quad 0.04 \mathrm{M}$ citric acid $p \mathrm{H} 6 \cdot 1$

Gel: $\quad 0.002 \mathrm{M}$ citric acid p $\mathrm{H} 6 \cdot 3$

Both buffers adjusted to $p \mathrm{H}$ with $\mathrm{N}$-(3-aminopropyl)-morpholine Gels were run for 6 hours at 20 volts $/ \mathrm{cm}$ constant voltage

(3) TVB (modified from Schwaegerle \& Schaal, 1979)

$\begin{array}{ll}\text { Electrode: } & 0.5 \mathrm{M} \text { Tris } \\ (p \mathrm{H} 8.0) & 0.65 \mathrm{M} \text { boric acid } \\ & 0.016 \mathrm{M} \text { EDTA, di sodium salt } \\ \text { Gel: } & 1 \text { in } 5 \text { dilution of electrode buffer }+0.04 \mathrm{mM} \text { NADP } \\ (p \mathrm{H} 8.0) & \end{array}$

Gels were run for 4.5 hours at $40 \mathrm{~mA}$ constant current 
comparisons were tested for homogeneity by a genic contingency chi-square analysis (Workman and Niswander, 1970). Multi-locus comparisons involved the computation of mean genetic identity $(\bar{I})$ values (Nei, 1972) for each pairwise combination of populations.

\section{RESULTS}

\section{Zymograms}

Initial screening for suitable enzyme systems was carried out on Termonbarry pitcher plants. Of the 25 enzymes investigated 11 showed no significant specific activity. These were (EC number): aconitase (4.2.1.3), acid phosphatase (3.1.3.2), alkaline phosphatase (3.1.3.1), adenosine deaminase (3.5.4.4), aldolase (4.1.2.13), fumarase (4.2.1.2), glycerol-3-phosphate dehydrogenase (1.1.1.8), lactate dehydrogenase (1.1.1.27), mannose phosphate isomerase (5.3.1.8), peroxidase (1.11.1.7) and shikimate dehydrogenase (1.1.1.25). These enzymes were not investigated further. The remaining 14 enzyme systems showed specific activity. These are detailed in table 3 .

At least 100 individuals were screened for the 14 enzyme systems. From the resulting zymograms a conservative estimate of the number of encoding loci was made and those loci suitable for routine population screening (i.e., giving clear, consistent and repeatable resolution in all individuals) were identified. This information is summarised in table 3 .
In each case enzyme expression in pitcher hood tissue was found to be representative of the whole plant, no expression of additional loci being apparent from extracts of other tissues. Extracts from developing and mature pitcher hoods showed only quantitative differences in locus expression.

Three diallelic polymorphisms were observed. The variant alleles $6 P g$ (75) and $M d h-4$ (110) (or similar) have previously been described (Schwaegerle and Schaal, 1979). The absence of a heterodimeric allozyme in zymograms of pollen (haploid tissue) from heterozygous plants confirmed the genetic bases of these polymorphisms in the present study. Phosphoglucomutase resolved as a single anodal zone of activity. Two single banded (homozygotes) and a double banded (heterozygote) phenotypes were observed. This was indicative of a diallelic polymorphism for a monomeric enzyme at a single locus. The variant allele was termed Pgm (85). This polymorphism has not previously been described in $S$. purpurea.

\section{Population data}

At the four sites where subsampling $(4 \times 25$ individuals) was performed no statistical differences in genotype numbers among subsamples were found. Thus each site was treated as a single sample of 100 plants. The allele frequency data for all populations at each of the polymorphic loci is presented in table 4. Only one case of statistically significant departure from Hardy-Weinberg pro-

Table 3 Experimental conditions and genetic interpretations for the enzymes yielding specific staining following starch gel electrophoresis

\begin{tabular}{|c|c|c|c|c|c|c|}
\hline Enzyme & $\mathrm{EC}$ number & Abbrev. & Buffer* & Locit & Screen $\ddagger$ & Polymorphic \\
\hline Alcohol dehydrogenase & 1.1.1.1 & $\mathrm{ADH}^{\|}$ & TVB & 1 & 1 & No \\
\hline Aspartate aminotransferase & 2.6.1.1 & AAT & CAM & 1 & 1 & No \\
\hline Malic enzyme & 1.1.1.40 & ME & TVB & 2 & 1 & No \\
\hline Xanthine dehydrogenase & 1.2.1.37 & $\mathrm{XDH}$ & TCB & 1 & 1 & No \\
\hline Glutamate dehydrogenase & 1.4.1.2 & $\mathrm{GDH}^{\|}$ & TVB & 1 & 1 & No \\
\hline Glucose phosphate isomerase & 5.3.1.9 & GPIll & TVB & 2 & 2 & No \\
\hline Isocitrate dehydrogenase & 1.1.1.42 & IDH & CAM & 2 & 1 & No \\
\hline Phosphoglucomutase & 2.7 .5 .1 & PGM & CAM & 1 & 1 & Yes \\
\hline Valyl-leucine peptidase & 3.4.11.- & PEP\|l & TCB & 2 & 2 & No \\
\hline Diaphorase & 1.6 .4 .3 & DIA & CAM & 3 & 1 & No \\
\hline Esterase & 3.1.1.- & EST & TCB & 2 & 0 & $?$ \\
\hline
\end{tabular}

\footnotetext{
* Electrophoretic buffer systems-see table 2.

$\uparrow$ Putative number of loci.

$\ddagger$ Usable in routine population screening.

"Screened in Schwaegerle and Schaal (1979) study (10 loci).
} 
Table 4 Allele frequency data and test for homogeneity (Workman and Niswander, 1970) for each polymorphic locus among Irish S. purpurea populations

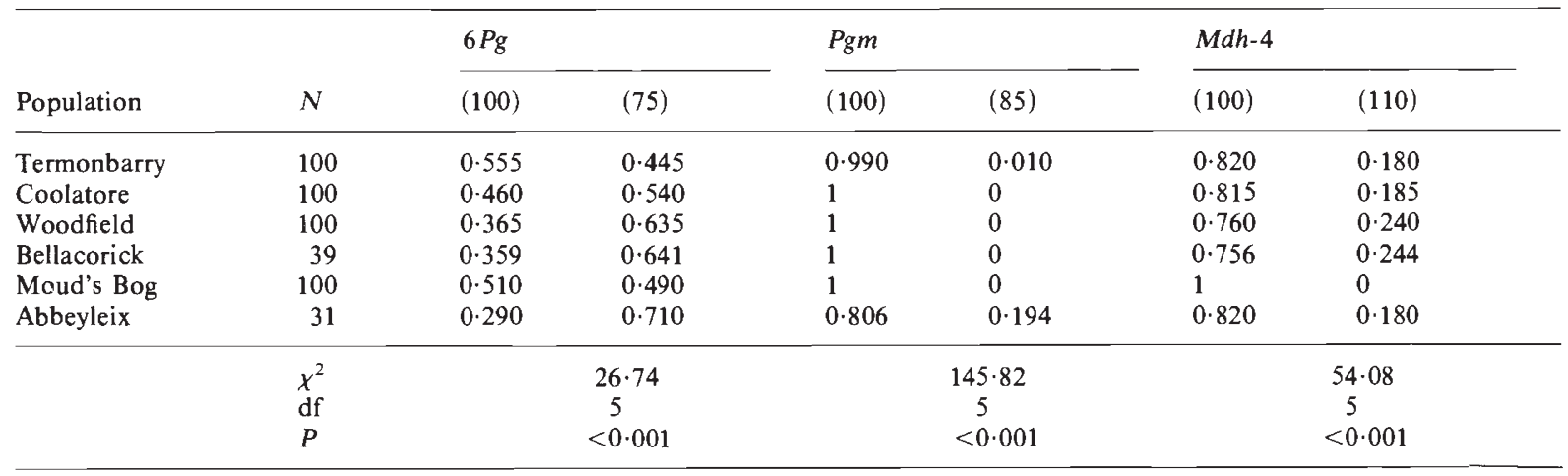

portions was noted (Abbeyleix, $6 P g ; P<0 \cdot 01$ ), where a deficit of heterozygotes was observed. Linkage disequilibrium analyses were performed for all pairwise combinations of polymorphic loci in each population. From a total of 13 analyses significant gametic phase disequilibrium was apparent in two cases (Abbeyleix, $6 \mathrm{Pg} / \mathrm{Mdh}$ 4, $P<0 \cdot 05$; Bellacorick, $6 P g / M d h-4, P<0.05)$.

Although relatively low, the level of genetic variability in the initial Irish founder stock was within the range recorded for native North American populations (table 5(a)). (This comparison was based on the ten loci examined that were common to both studies-as indicated in table 3 ). A comparison among the Irish populations, based on the full 18 loci screened, indicates that, in general, the founding events have led to a reduction in the number of polymorphic loci, while heterozygosity levels have not been dramatically reduced (table 5(b)). However, the greatest reduction in heterozygosity was observed for the severest founding event (i.e., Moud's Bog; $n=2$ ).

The founder events have led to significant allele frequency differences among populations at all three polymorphic loci, table 4 . A matrix of mean genetic identity values $(\bar{I})$ between populations is given in table 6 , the values ranging between 0.9924 and 0.9999. A dendrogram constructed from these data is presented in fig. 2 . The closer the value of $\bar{I}$ to unity the closer related are the populations. The Moud's Bog and Abbeyleix populations were shown to be the most genetically distinct.

Table 5 Genetic variability in Irish and American $S$. purpurea populations

\begin{tabular}{|c|c|c|c|c|c|c|}
\hline \multirow[b]{2}{*}{ Population* } & & \multicolumn{2}{|c|}{ Polymorphic loci } & \multirow{2}{*}{$\begin{array}{l}\text { Mean number } \\
\text { of alleles }\end{array}$} & \multicolumn{2}{|c|}{ Heterozygosity } \\
\hline & & No. & per cent & & Obs. & Exp. \\
\hline \multicolumn{7}{|l|}{ (a) } \\
\hline Termonbarry & & 2 & 20 & $1 \cdot 20$ & 0.083 & 0.079 \\
\hline Ten & mean & $2 \cdot 6$ & 26 & $1 \cdot 31$ & 0.094 & 0.087 \\
\hline North & $\min$ & 1 & 10 & $1 \cdot 10$ & 0.050 & 0.040 \\
\hline American & $\max$ & 4 & 40 & $1 \cdot 50$ & $0 \cdot 162$ & $0 \cdot 173$ \\
\hline \multicolumn{7}{|l|}{ (b) } \\
\hline Termonbarry & $(?)$ & 3 & 17 & $1 \cdot 17$ & 0.047 & 0.045 \\
\hline Coolatore & $(?)$ & 2 & 11 & $1 \cdot 11$ & 0.036 & 0.044 \\
\hline Woodfield & (3) & 2 & 11 & $1 \cdot 11$ & 0.038 & 0.046 \\
\hline Bellacorick & (3) & 2 & 11 & $1 \cdot 11$ & 0.038 & 0.046 \\
\hline Moud's Bog & (2) & 1 & 6 & $1 \cdot 06$ & 0.030 & 0.028 \\
\hline Abbeyleix & (4) & 3 & 17 & $1 \cdot 17$ & 0.047 & 0.060 \\
\hline
\end{tabular}

(a) Based on 10 loci common to both studies. American data from Schwaegerle and Schaal (1979).

(b) Based on full 18 loci.

* Number of founders in parentheses. 
Table 6 Mean genetic identity values, $\bar{I}$ (Nei, 1972), for Irish $S$. purpurea populations. (Based on 18 loci)

\begin{tabular}{|c|c|c|c|c|c|c|}
\hline & & 1 & 2 & 3 & 4 & 5 \\
\hline 1 & Termonbarry & - & & & & \\
\hline 2 & Coolatore & 0.9993 & - & & & \\
\hline 3 & Woodfield & 0.9977 & 0.9991 & - & & \\
\hline 4 & Bellacorick & 0.9975 & 0.9989 & 0.9999 & - & \\
\hline 5 & Moud's Bog & 0.9982 & 0.9978 & 0.9956 & 0.9953 & - \\
\hline 6 & Abbeyleix & 0.9940 & 0.9960 & 0.9976 & 0.9977 & 0.9924 \\
\hline
\end{tabular}

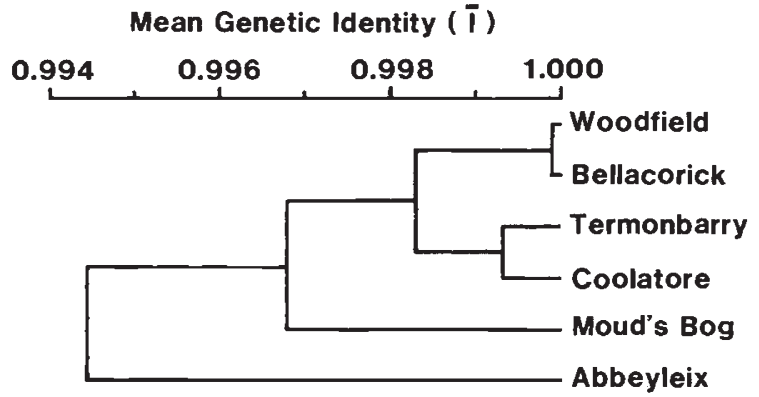

Figure 2 Dendrogram based on mean genetic identity values $(\bar{I}$, Nei 1972) for Irish $S$, purpurea populations.

\section{DISCUSSION}

Eleven enzymes failed to show specific activity following starch gel electrophoresis. Plant tissues present special problems in the isolation of enzymes owing primarily to the presence of inhibitory compounds such as phenolics and quinones (Loomis, 1974). Similar difficulties have been encountered in most plant electrophoretic studies (Gottlieb, 1981). However the number of loci available for study in $S$. purpurea was increased from ten (Schwaegerle and Schaal, 1979) to 18 in this study. Despite these additions the number of informative loci observed for Irish pitcher plant populations was low, only three polymorphic loci being scored. While this precluded a comprehensive study of the founder events, general underlying trends were evident.

The level of genetic variation in the initial founder stock at Termonbarry was within the range recorded for other North American populations. Therefore, although low, there is no evidence to suspect that this was primarily the result of a severe founder event. Indeed the presence of a rare allele (Pgm (85), frequency $=0.01)$ would suggest the number of original founders numbered at least 30-50 individuals. With the original planting in 1906 consisting of "seeds and rootstock" (Praeger,
1932), is is plausible that such relatively large numbers were involved.

It is a generally held view that founder events substantially reduce genetic variability. However theoretical considerations would suggest otherwise (Nei et al., 1975; Chakraborty and Nei, 1977). While rare alleles are undoubtedly lost during such events these contribute only minimally to average heterozygosity (the most commonly reported measure of genetic variability). $\bar{H}$ is mainly influenced by "mid frequency" alleles. Such alleles are likely, by chance sampling, to be well represented in founding stocks, maintaining relatively moderate levels of heterozygosity. This view was supported by the pitcher plant data. While, in all but the Abbeyleix sample, the founding event had resulted in the loss of the rare Pgm (85) allele, $\bar{H}_{\text {exp }}$ was only substantially reduced in the severest founder event (Moud's Bog). The latter reduction can be attributed to the loss of a "mid frequency" allele $(M d h-4(110))$, in this population. The repeated founder event experienced by the Woodfield population had no apparent additional effect on heterozygosity level.

It is clear from the above considerations that the effects of founder events on genetic variability measurements are largely dependent upon the pattern of variation present in the original stock. In this respect the Termonbarry population, with one rare and two mid-frequency diallelic polymorphisms, presents an atypical, and analytically restrictive, situation. Had a number of low frequency polymorphisms (i.e., variant allele frequency of around $0 \cdot 1$ ) been identified a more varied range of heterozygosity values across the founded populations could have been expected.

The founding events and subsequent $\mathrm{drift} /$ selection have had a more dramatic impact on differentiation, all three loci showing highly significant allele frequency differences among the populations. The two most genetically distinct populations (lowest $\bar{I}$ values) illustrate the two basic mechanisms by which differentiation can 
arise in such situations: (a) by overall loss of polymorphic loci-Moud's Bog; and (b) by the chance occurence and proliferation of a rare allele-Abbeyleix. Considering their recent derivations from a single population it was not surprising that $\bar{I}$ values for the Irish populations were generally higher than those recorded for widely geographically separated North American populations (range 0.934-0.999, mean $=0.974$; Schwaegerle and Schaal, 1979).

The occurrence of heterozygote deficiency and linkage disequilibrium among loci in the two smallest populations probably reflects non random sampling, i.e., from distinct family groups. Such inbreeding was particularly evident in the Abbeyleix population where 28 of the 31 individuals present were found in four distinct groups of around one metre diameter, possibly reflecting the four "clumps" originally transplanted (Nelson and De Vesci, 1981). Each group had a unique genotype combination for the three polymorphic loci. Despite their close proximity (max. distance between groups being six metres) there was no evidence of significant gene flow among the separate groups. For example the $M d h-4(110)$ allele was restricted to one group, the Pgm (85) allele to two groups. This could not be solely attributed to vegetative reproduction, a number of distinct seedlings being sampled.

From the limited data available there was no indication that the present status of the $S$. purpurea populations in Ireland was correlated to either the presence or absence of any particular allele or to overall heterozygosity. Rather, observations would suggest that environmental factors were the main influence. The largest colonies were those in the wetter bogs and within sites the major concentrations of plants were to be found in the wettest regions. Therefore the allele frequency differences may be attributed solely to the founding events and subsequent genetic drift.

Acknowledgements: We would like to thank A. Ferguson for critically reading the manuscript. This study was funded through a research grant awarded by the National Board of Science and Technology.

\section{REFERENCES}

CHAKRABORTY, R. AND NEI, M. 1977. Bottleneck effects on average heterozygosity and genetic distance with stepwis: mutation models. Evolution, 31, 347-356.

CLAYTON, J. W. AND TRETIAK, D. N. 1972. Amine-citrate buffers for $\mathrm{pH}$ control in starch gel electrophoresis. J. Fish. Res. Bd Can., 29, 1169-1172.

FERGUSON, A. 1980. Biochemical Systematics and Evolution. Blackie, Glasgow.

FOSS, P. J. AND O'CONNELL, C. A. 1984. Further observations on Sarracenia purpurea L. in county Kildare (Hi9). Ir. Nat. J., 21, 264-266.

FOSS, P. J. AND O'CONNELL, C. A. 1985. Notes on the ecology of Sarracenia purpurea L. on Irish peatlands. Ir. Nat. J., $21,440-443$.

GOTTLiEB, L. D. 1981. Electrophoretic evidence and plant populations. In Reinhold, L., Harborne, J. and Swain, T. (eds) Progress in Phytochemistry, Vol. 7, Pergamon, Oxford, pp. 2-46.

HARRIS, H. AND HOPKINSON, D. A. 1976. Handbook of Enzyme Electrophoresis in Human Genetics. NorthHolland. Amsterdam.

HILL, W. G. 1974. Estimation of linkage disequilibrium in randomly mating populations. Heredity, 33, 229-239.

KERTLAND, M. P. H. 1968. Sarracenia purpurea as an introduced plant in Ireland. Ir. Nat. J., 16, 50-51.

LOOMIS, W. D. 1974. Overcoming problems of phenolics and quinones in the isolation of plant enzymes and organelles. In Fleisher, S. and Packer, T. L. (eds) Methods in Enzymology, Vol. 31, Academic press, London, pp. 528544.

NEI, M. 1972. Genetic distances between populations. Amer Natur., 106, 283-292.

NEI, M., MARUYAMA, T. AND CHAKRABORTY, R. 1975. The bottleneck effect and genetic variability in populations. Evolution, 29, 1-10.

NELSON, E. C. AND DE VESCI, S. 1981. Sarracenia purpurea L. naturalised in county Laois (H14). Ir. Nat. J., 20, 253.

NEWELL, J. P. 1968. Notes on Sarracenia purpurea. Ir. Nat. J., 16,108 .

POWELL, J. R. 1978. The founder-flush speciation theory: an experimental approach. Evolution, 32, 465-474.

PRAEGER, R. L. 1932. Noteworthy plants found in or reported from Ireland. Proc. R. Ir. Acad., 41, 95-124.

SCHWAEGERLE, K. E. AND SCHAAL, B. A. 1979. Genetic variability and founder effect in the pitcher plant Sarracenia purpurea L. Evolution, 33, 1210-1218.

VAlleJOS, C. E. 1983. Enzyme staining activity. In Tanksley, S. D. and Orton, T. J. (eds) Isozymes in Plant Genetics and Breeding, Part A, Academic Press, Oxford, pp. 469-516.

WORKMAN, P. L. AND NisWANDER, J. D. 1970. Population studies on Southwestern Indian tribes. II. Local genetic differentiation in the Papago. Amer. J. Hum. Genet., 22, 24-49. 